\title{
INOVAÇÃO E DESTRUIÇÃO CRIADORA E OS DESAFIOS ATUAIS E INSTITUCIONAIS DA INDÚSTRIA MUSICAL
}

\author{
Ednilson Silva Felipe e Elvira Carolina Scapin Martins
}

\begin{abstract}
RESUMO
Segundo Schumpeter e os neoschumpeterianos, a inovação é o motor que mantém em movimento a máquina capitalista. Nessa análise, inovação não somente proporciona às empresas um lucro e um monopólio extraordinário, mas também provoca, em vários níveis, um processo de destruição criadora. Sendo o elemento que explica as transformações dinâmicas na economia, a destruição criadora pode abranger produtos e processos e pode abalar a estrutura de firmas e setores inteiros. Esse é o movimento que esse artigo descreve em relação à indústria musical. Abalada constantemente por uma sequência de inovações radicais, a indústria fonográfica tem experimentado fortemente o processo de destruição criadora. Ao mudar as possibilidades de gravação e de consumo da música, as recentes transformações diminuíram o papel das grandes gravadoras e distribuidoras. Entretanto, como o processo é ininterrupto, ainda se verifica mudanças acontecendo e não se sabe ao certo que formato tomará essa indústria nos próximos anos.
\end{abstract}

PALAVRAS-CHAVE: inovação, destruição criadora, indústria musical, instituições

\begin{abstract}
According to Schumpeter and the Neoschumpeterians, the innovations is the engine that to keep moving the capitalist machine. In this analyze, innovation not only gives firms extraordinary profit and monopoly, but also causes, at various levels, a creative destruction process. Being the element that explains the dynamic changes in the economy, the creative destruction may cover products and process and can shake the structure of firms and economic sectors et all. This is the movement that this article describes in relation to the musical industry. Shaken constantly by a sequence of radical innovations, the phonograph industry has strongly experienced the force of the creative destruction process. By changing the possibilities of recording and music consumption, recent transformations have reduced the role of major labels and distributors. However, as the process is continuous, there still change happening and it is not known for sure what format will take this industry in the future.
\end{abstract}

KEY WORDS: innovation, creative destruction, music industry, institutions.

\section{INTRODUÇÃO}

Conforme Schumpeter e neo-schumpeterianos, o processo de destruição criadora representa, em seus diversos níveis, o processo de mutação nas estruturas do capitalismo. O surgimento de inovações tem a capacidade de abalar as estruturas econômicas e institucionais de empresas, indústrias, setores inteiros e, nos casos paradigmáticos, do sistema econômico como um todo. A indústria da música, desde seu surgimento até os dias de hoje, passou por diferentes fases, cada uma delas ligada a uma tecnologia diferente. A busca por inovações que melhorassem a qualidade sonora da gravação e a capacidade da reprodução das músicas, assim como reduzissem os custos de produção e distribuição, não se limitou apenas ao âmbito das gravadoras e envolveu empresas de outros setores, como as empresas de aparelhos eletrônicos e de tecnologias de informação e comunicação. No decorrer de seu 
desenvolvimento tecnológico, a indústria musical foi marcada por mudanças estruturais, estratégicas e institucionais.

O objetivo desse artigo é mostrar as mudanças estruturais e institucionais que ocorreram desde o surgimento do fonógrafo até os atuais formatos virtuais. Essa retrospectiva histórica é importante para observar que a atual crise que a indústria fonográfica não é a primeira e que as crises anteriores também foram provocadas pela introdução de uma inovação e pela ausência de previsão normativa. O surgimento de novos suportes físicos para a música implicou em mudanças nas estruturas produtivas, nos hábitos de consumo, nas relações entre os atores envolvidos no negócio da música e exigiu adequações nos direitos autorais. As incertezas, as externalidades negativas e a realocação de recursos e posições de poder que a indústria fonográfica presenciou foram consequências diretas de inovações tecnológicas criadas por empresas ligadas direta ou indiretamente à música.

O artigo está dividido em XX partes além dessa introdução. Na que segue, discute-se o conceito de inovação e destruição criadora, instaurado por Schumpeter e posteriormente desenvolvido pelos neoschumpeterianos. No item três discute-se a fase analógica da música e em seguida a era digital. Por fim o último item discute algumas mudanças mais recentes na indústria musical com o fenômeno da internet e as inúmeras possibilidades de consumo da música de forma gratuita. Segue-se depois os comentários finais e referências.

\section{SCHUMPETER, AS INOVAÇÕES E A DESTRUIÇÃO CRIADORA.}

Schumpeter analisou detidamente o papel da inovação como motor do desenvolvimento capitalista. Para o autor, a inovação engloba “a abertura de novos mercados, estrangeiros e nacionais” (SCHUMPETER, 1961, p. 110), “a introdução de novas mercadorias, novas técnicas, novas fontes de suprimento, novo tipo de organização” (p. 112), ou ainda, a “abertura de novas fontes de suprimento de materiais, novos canais de distribuição, reorganização da indústria” (p. 166). Uma inovação deve ser entendida como uma nova combinação dos fatores de produção, cujos impactos variam desde a redução dos custos e aumento de produtividade até a criação e destruição de novos mercados ou até mesmo setores econômicos inteiros. A inovação é concebida como o cerne das mudanças que tendem a melhorar a vida material da sociedade. Algumas inovações são capazes de fazer expandir o mercado de forma a melhorar o nível de vida da sociedade. Entretanto, o processo inovativo não é harmônico e tende a modificar a estrutura existente na economia. Trata-se de um processo de “destruição criadora”, ou de contínua mutação industrial 
[...] que revoluciona incessantemente a estrutura econômica a partir de dentro, destruindo incessantemente o antigo e criando elementos novos. Este processo de destruição criadora é básico para se entender o capitalismo. É dele que se constitui o capitalismo e a ele deve se adaptar toda a empresa capitalista para sobreviver (SCHUMPETER, 1961, p. 110).

O processo de "destruição criadora" é inerente ao sistema capitalista e envolve a criação de novos métodos de transformação produtiva, ou novas tecnologias, que podem destruir os antigos métodos ou as antigas tecnologias. Vale ressaltar, contudo, que este processo não é mecânico nem automático. Novas e velhas tecnologias podem conviver simultaneamente, de forma que nem sempre as primeiras substituem completamente as últimas.

Para Perez (2002, p. 223), este processo de substituição é uma transição lenta e dolorosa entre o novo contra o velho, como foi observado "when cargo railways and ships were gradually replaced by trucks and airplanes, when natural materials were replaced by synthetics or when the reign of radio was replaced by that of TV or plastic records by CD's"

Ainda segundo a autora, o advento de uma nova tecnologia pode exigir mudanças em toda uma cadeia produtiva, modificando-a desde os fornecedores até os consumidores, e, às vezes, reorganizando as posições relativas dos jogadores e alterando as regras do jogo. Não é uma mudança apenas no tipo de produto, mas também na sua forma de produção e comercialização, no poder relativo dos agentes envolvidos e na forma como o consumidor adquire o bem. Assim temos que

\footnotetext{
Creative destruction implies the decline of some activities as a necessary element in the growth of others, and when activities decline and disappear they may leave behind a pattern of social life shaped by an institutional and organizational structure that has lost its economic raison d'être. Similarly, the growth of new activities may be well in advance of creation of supporting social arrangements (METCALFE, 2001, p. 566)
}

Em outras palavras, o processo de destruição criadora envolve a eliminação de atividades obsoletas e a realocação dos fatores de produção para as novas atividades. Logo, uma inovação, ou um conjunto de inovações, pode ter a capacidade de provocar fortes consequências para uma indústria, setor ou todo um mercado, afetando o lado econômico e também o social e o institucional (leis, regulamentos, hábitos de consumo, etc).

Segundo Perez (2002), a destruição criadora se manifesta em períodos de revoluções tecnológicas ou industriais, desencadeadas por um "fator chave" que tem a capacidade de originar uma "constelação" de outras inovações. Estas revoluções são processos não contínuos que ocorrem em explosões discretas e sistemáticas a cada 50 ou 60 anos. Elas representam uma ruptura do estado anterior provocando reações que não são apenas 
localizadas e adaptativas, mas que promovem profundas mudanças em toda a economia. Para Schumpeter (1961, p. 110)

Essas revoluções não são permanentes, num sentido estrito; ocorrem em explosões discretas, separadas por períodos de calma relativa. O processo, como um todo, no entanto, jamais para, no sentido de que há sempre uma revolução ou absorção dos resultados da revolução, ambos formando o que é conhecido como ciclos econômicos.

É através das revoluções tecnológicas que as sociedades são profundamente abaladas (PEREZ, 2002). A introdução de uma inovação e sua consequente difusão pode envolver alterações nas rotinas ${ }^{1}$, na formação de competências, no capital físico e humano da empresa, e, dependendo do tipo de inovação, pode afetar não apenas as empresas ou setor no qual originalmente foi criada, mas também envolver indústrias e setores de outras áreas.

Para Schumpeter (1961) e Perez (2002), a dupla natureza da destruição criadora torna o processo inovativo amplamente complexo, já que não é apenas a força que gera o crescimento econômico, mas também é a causa de recessões e do comportamento cíclico da economia, no momento em que este processo tem a capacidade de alterar drasticamente os alicerces e a própria existência das firmas. Por isso, muitas firmas são apreensivas quanto ao surgimento de novos produtos, tecnologias ou técnicas.

\begin{abstract}
Velhas firmas e indústrias tradicionais, estejam ou não diretamente expostas à fúria dos elementos, vivem ainda assim em meio da eterna tempestade. Surgem, no processo da destruição criadora, situações em que muitas firmas que afundam teriam podido continuar a navegar vigorosa e utilmente se tivessem podido atravessar determinada tormenta. A parte as crises e situações gerais, surgem situações locais em que a rápida transformação da conjuntura, (...) desorganiza de tal maneira a indústria, a ponto de infringir prejuízos absurdos e ocasionar um desemprego evitável (SCHUMPETER, 1961, p.117-118).
\end{abstract}

Nenhuma empresa pode se sentir segura e confortável quando a economia está - e sempre está - engendrando um processo de destruição criadora. Empresas mais tradicionais, mesmo aquelas que detenham o monopólio de um mercado, sofrem a constante pressão da concorrência, tanto potencial quanto efetiva. Para garantir sua sobrevivência no mercado, a firma precisa estar apta às mudanças externas, de forma que ela tenha a capacidade de mudar suas rotinas, sua organização, sua base tecnológica ou até mesmo o ramo em que atua.

É razoável que firmas menos eficientes deem espaço às firmas mais produtivas. Caso empresas obsoletas não abandonem o mercado, a má alocação de fatores de produção escassos pode elevar seus custos. Todavia, como observado por Freeman e Soete (2008), a eliminação de uma ou mais indústrias representa a perda de empregos, que mesmo liberando

\footnotetext{
${ }^{1}$ As rotinas são as características fundamentais, persistentes e hereditários da empresa, que podem ser modificadas deliberadamente para atender as modificações do ambiente.
} 
mão-de-obra para as novas atividades, geralmente requerem um novo conjunto de habilidades, ou podem surgir em outra localidade.

Ou seja, enquanto uns lucram e ganham com as inovações, existem outros agentes que se deparam com perdas lastimáveis - empresas falidas, desemprego, perda de capital físico e humano - principalmente quando a economia ainda está se ajustando às novas condições trazidas pelas inovações.

\section{A ERA ANALÓGICA: A CONSTRUÇÃO E CONSOLIDAÇÃO DA INDÚSTRIA FONOGRÁFICA}

Até o final do século XIX, o consumo da música só era possível em espetáculos ao vivo, devido à inexistência de aparelhos e técnicas de gravação de som. O surgimento da indústria fonográfica ocorreu devido a três inovações: o fonógrafo, o gramofone e a técnica de duplicação de discos. O fonógrafo foi considerado o primeiro aparelho capaz de gravar e reproduzir sons, mas apenas permitia a gravação da música em um mesmo cilindro, sem a capacidade de copiá-la para outro. A possibilidade de criar uma indústria voltada a produção em massa só foi possível com o surgimento da reprodutibilidade técnica do som ou técnica de duplicação de discos ${ }^{2}$. Essa técnica foi desenvolvida em 1888 através da criação do gramofone por Emile Berliner. O novo aparelho não utilizava cilindros e sim discos feitos de goma-laca $^{3}$ (posteriormente os discos seriam feitos de vinil ${ }^{4}$ ) que eram duplicados a partir de um disco matriz (DE MARCHI, 2005; HUYGENS et al, 2009).

A partir disso, a música podia ser comercializada por meio de um bem tangível, não sendo mais apenas um serviço representado pelas interpretações e execuções ao vivo destinadas a um restrito número de pessoas (LOSSO, 2008). Dessa forma, surgia o mercado de música destinada ao consumo privado ou doméstico.

No entanto, o uso dos gramofones não se limitou ao ambiente doméstico, e muitos estabelecimentos comerciais utilizaram desse equipamento para a reprodução de músicas, dispensando as apresentações ao vivo. Como apontado por Losso (2008), pela interpretação da lei naquele período, no momento em que o autor cedia a publicação de sua obra para a

\footnotetext{
${ }^{2}$ Reprodutibilidade técnica ou duplicação de disco significa a possibilidade de produzir uma cópia do conteúdo através de uma mesma matriz (DE MARCHI, 2005)

${ }^{3}$ Goma-laca é uma resina secretada pelo inseto Kerria lacca, encontrado nas florestas da Índia e Tailândia. O material bruto é refinado em diversos graus para diferentes propósitos.

${ }^{4}$ Vinil (também chamado de policloreto de polivinilha ou policloreto de vinil ou cloreto de vinila) é um material plástico composto por 57\% de cloro e 43\% de eteno (derivado do petróleo).
} 
gravação, ele também consentia seu uso para qualquer finalidade, dispensando tais estabelecimentos de alguma contraprestação autoral. Os autores-compositores não tinham nenhum controle da execução de suas criações e se haveria retribuições autorais.

Além disso, os músicos recebiam por performance gravada. Não recebiam nenhuma percentagem relativa as vendas dos discos nem pelos direitos autorais. Todo o lucro obtido pelas vendas de discos era retido pelas gravadoras. Do ponto de vista dessas, o fonograma não deveria ser objeto protegido pelos direitos autorais, já que estes, à época, abrangiam apenas obras em documento legalmente aceito. No caso da música, este documento era a partitura.

Outro argumento utilizado pelas gravadoras era que os fonogramas democratizaram o acesso à música e beneficiavam compositores e artistas por ajudar na divulgação das obras, já que estimulavam os consumidores a irem aos concertos ou a comprarem as partituras das editoras (DE MARCHI, 2011).

Assim, a primeira crise do autor pode ser resumida pela insegurança que "passou a afligir os agentes envolvidos no novo modelo de negócios, principalmente os compositores, os artistas e os investidores culturais, dada a imprevisão normativa quanto aos meios de fixação" (LOSSO, 2008, p. 37). Tal crise levou a buscar respostas que fossem de encontro às necessidades de proteção do direito patrimonial e moral ${ }^{5}$ de compositores e intérpretes cujas obras estavam sendo gravadas em discos e reproduzidas em ambientes públicos.

[...] a primeira crise do direito do autor na música foi causada pela introdução da tecnologia da fixação de sons em meio físico para posterior audição e consistiu, principalmente: i) no início de uma forte indústria fonográfica, que nas décadas seguintes passou a decidir o que seria escutado pelo público; ii) na constatação da mudança da caracterização da música de serviço para produto, com as implicações sociais e jurídicas decorrentes; e iii) no estabelecimento de dúvida quanto ao mecanismo de controle da execução musical e respectiva remuneração aos compositores (LOSSO, 2008, p. 43, grifo do autor).

A solução veio em 1908, quando ocorreu a primeira revisão da Convenção de Berna, em Berlim, em que foi estabelecido que o direito de autor também cobriria as reproduções mecânicas (discos e rolos de pianos automáticos), concedendo o chamado direito moral aos compositores (DE MARCHI, 2011).

De acordo com Huygens et al (2009), nessa primeira fase da indústria fonográfica, o foco estava na venda de equipamentos e discos e não propriamente na divulgação da música em si. As primeiras gravadoras eram geridas por engenheiros e técnicos preocupados na

\footnotetext{
${ }^{5} \mathrm{O}$ direito patrimonial trata sobre o direito de explorar economicamente uma obra intelectual, enquanto que o direito moral se refere à autoria da criação da obra (LEMOS et al, 2011).
} 
melhoria técnica dos equipamentos, dos processos de fabricação e de gravação da música. Tais gravadoras trabalhavam com compositores e intérpretes de seu próprio elenco, com os quais mantinham contratos de exclusividade. Sua única preocupação era com a venda de produtos e não com a exploração do direito do autor e com sua devida remuneração. Essa lógica somente iria mudar com a popularização do rádio já na década de 1920.

O rádio proporcionou maior comodidade aos usuários e logo se tornou um forte concorrente do gramofone como bem de consumo doméstico. Além disso, mostrou uma nova perspectiva para o mercado ao mostrar a importância da divulgação da obra musical e, por consequência, dos autores e de seus intérpretes. Nessa conjuntura, a indústria fonográfica presenciou sua primeira crise estrutural.

Mas o surgimento do rádio também trouxe a segunda crise no direito do autor. Isso porque as transmissões radiofônicas se davam por interpretações ao vivo (por autores ou intérpretes) ou por meio de fonogramas executados no gramofone. Os donos dessas companhias sofreram severas reclamações de compositores, intérpretes e das gravadoras. Os primeiros recorriam a justiça contra a exploração não-autorizada de suas obras. As segundas, se preocuparam com a utilização não-remunerada de suas gravações, isto é, as rádios compravam os discos, mas não pagavam pela transmissão do conteúdo contido nestes discos. Segundo Losso (2008, p. 51)

[...] a segunda crise do direito de autor na música foi causado pelo advento da radiodifusão, tendo ocorrido em tempo quase simultâneo à primeira crise, da fixação de sons em meio físico, e consistiu: i) no início de um forte segmento de radiodifusão; ii) na incerteza jurídica que passou a afligir, num primeiro momento, os compositores e, num segundo momento, os produtores musicais, no que diz respeito à utilização de fonogramas pelas emissoras e respectivas retribuições autorais; iii) no desenvolvimento dos que viriam a ser conhecidos como direitos conexos aos autorais, pela garantia legal que passaram a ter os organismos de radiodifusão.

Se por um lado, as transmissões radiofônicas ajudaram na propagação de obras musicais, o que contribuiu para o reconhecimento e o apreço do público em relação aos músicos, por outro lado, os compositores enfrentaram diversos problemas já que muitos deles ainda foram contratualmente obrigados a simplesmente ceder seus respectivos direitos de execução radiofônica da obra à gravadora que os assumia por meio da via contratual,

[...] a posição jurídica do autor-compositor, sujeito protagonista do direito de autor, para, em nome dele, ou em seu próprio nome quando cessionária dos direitos patrimoniais, ou representada por sociedade de defesa dos direitos autorais, pleitear pagamentos referentes à execução pelas rádios (LOSSO, 2008, p. 46). 
Assim, como na primeira crise do autor, não havia uma previsão normativa em relação aos problemas jurídicos que a nova tecnologia trouxe. Fica evidente que é impossível para a lei vigente, em qualquer época, prever os problemas procedentes de uma inovação, mas cabe a ela tentar encontrar um consentimento entre os diferentes (e até mesmo conflitantes) interesses dos agentes envolvidos. Apesar do direito do autor visar a preservação do direito de escritores, intelectuais e artistas, ele evoluiu de forma a também atender aos interesses de outros agentes envolvidos na comercialização de obras artísticas e literárias.

No caso da música, na primeira crise do autor e a busca por redefinição desses direitos resultou na regulação do uso das canções em suportes físicos. Na segunda crise, a revisão da Convenção de Berna em 1928 e depois em 1948 regulou as atividades de radiodifusão, cabendo a cada país a competência de regular os direitos referentes a autorização da comunicação das obras ao público pela radiodifusão, mas isso não significou que os artistas tiveram mais autonomia em relação a suas obras, visto a cessão contratual que muitos faziam às $s$ gravadoras.

Paralelo a isso, tanto as produtoras de fonogramas quanto as companhias de radiodifusão começaram uma corrida em busca de novos materiais, novos equipamentos de gravação e novos aparelhos de reprodução. Inaugurou-se uma competição tecnológica: a competição por novos formatos e novos equipamentos que fossem mais baratos e de melhor qualidade sonora. Enquanto as gravadoras queriam impulsionar o consumo massificado de discos, as rádios buscavam melhorar as transmissões radiofônicas (DE MARCHI, 2005; NAKANO, 2010).

A busca por novas tecnologias trouxe para o mercado as caixas amplificadoras, a utilização de microfones e o uso da gravação elétrica. A gravação elétrica, comparada com a mecânica, apresentou melhor qualidade sonora e maior capacidade de gravação. O avanço tecnológico implicou no surgimento de artistas que se especializaram em técnicas de estúdio, para adequar suas canções aos novos equipamentos de gravação, o que deu início a uma relação mais próxima entre a criação musical e o desenvolvimento tecnológico (DE MARCHI, 2005).

Ao mesmo tempo, de acordo com De Marchi (2011), devido à crise de 1929 e ao acirramento da competição, algumas gravadoras, para não irem à falência, passaram por fusões ou foram adquiridas pelas empresas radiofônicas. Estas movimentações de capital e de propriedade deram origem as grandes gravadoras. Os engenheiros que geriam as gravadoras na primeira fase foram substituídos por tecnocratas preocupados com a racionalização da produção e em garantir que suas empresas estivessem a frente dos avanços tecnológicos. 
O mercado da música se intensificou. Apesar da diminuição da quantidade e da variedade de novos lançamentos, houve o aumento da quantidade comercializada. Em 1938, as gravadoras norte-americanas, por exemplo, faturaram com a venda de discos aproximadamente US\$ 26 milhões em comparação aos US\$ 6 milhões em 1933.

A década de 1940 foi um outro marco para a produção em massa da música, estabelecendo um novo modelo de consumo, em que a venda dos conteúdos em discos tornava-se mais importante do que os equipamentos domésticos. Ou seja, a maior parte das receitas das gravadoras provinha da música gravada, através da venda de discos e de direitos cobrados para rádios, jukeboxes e cinema. De acordo com Losso (2008), a radiodifusão passou a exercer a função de promover a música e passou a não ser mais vista como concorrente das gravadoras. Ao enviar singles para serem tocados nas rádios, o intuito das gravadoras era impulsionar a imagem do artista e induzir o público a comprar os discos.

Até a década de 1950, a indústria fonográfica foi estruturada em um oligopólio dominado por poucas empresas, que estavam à frente das pesquisas de novos formatos e novos métodos de gravação. Elas tinham as propriedades dos estúdios de gravação e o acesso privilegiado dos meios de promoção e divulgação das músicas, ou seja, eram verticalizadas, dominando as quatro etapas de produção: criação, produção, divulgação e distribuição.

Quadro 1: Etapas da Cadeia Produtiva da Indústria Fonográfica

\begin{tabular}{|l|l|l|l|}
\hline \multicolumn{1}{|c|}{ CRIAÇÃO } & \multicolumn{1}{c|}{ PRODUÇÃO } & \multicolumn{1}{c|}{ DIVULGAÇÃO } & \multicolumn{1}{c|}{ DISTRIBUIÇÃO } \\
\hline Atividade artística & Gravação & Shows & Logística \\
composição & Publicação & Mídia (Rádio, TV, canais & Percepção da demanda \\
Seleção dos artistas & Masterização & de streaming) & Transporte \\
& Manufatura & Kits promocionais & Armazenamento \\
& & Comerciais & \\
\hline
\end{tabular}

Fonte: Elaboração própria

Como apontado por Losso (2008), o músico que almejava desenvolver carreira no mercado precisava ter vínculo com alguma gravadora, visto a impossibilidade de percorrer, por conta própria, todos os elos em que se formaram a indústria musical. Ou seja, era impeditiva a possibilidade de poder gravar um disco por outro meio, além de que os canais de divulgação, como a radiodifusão, estavam sobre o controle das grandes companhias. O aumento do poder econômico de gravadoras e empresas de radiodifusão implicou na maior pressão dos atores envolvidos nessas atividades em garantir proteção jurídica.

Em 1961, a Convenção de Roma para a proteção dos intérpretes, produtores e organismos de radiodifusão, que estatuiu a garantia dos direitos conexos, isto é, os direitos que protegiam, judicialmente, intérpretes, compositores, produtores de fonogramas e 
organismos de radiodifusão contra a utilização não autorizada, respectivamente, de suas execuções, reproduções fonográficas e das fixações de suas retransmissões (LOSSO, 2008). Isso significou, em nível internacional, que o direito do autor, que a princípio deveria proteger os criadores de obras artísticas e intelectuais, foi ampliado para também salvaguardar os intérpretes, as gravadoras e as empresas de radiodifusão.

Paralelo a isso, em 1948, foi lançado o Long Play (LP) ${ }^{6}$, considerado a "grande inovação” da indústria fonográfica. O LP mudou o padrão de consumo ao propor o conceito de estética do álbum: os discos passaram a ser visto como obras de arte em si. Por causa do design das capas dos discos, a durabilidade e a alta qualidade sonora, o consumo do LP chegou a ser comparado com o dos livros (DE MARCHI, 2005).

O lançamento da fita cassete (K-7) pela Phillips em 1963, contribuiu para a desconcentração da indústria. Por causa da facilidade de seu manuseio e seu baixo custo (comparado a tecnologias anteriores) permitiram seu uso para gravações sonoras não profissionais, o que incentivou o surgimento de estúdios caseiros e a gravação de novos estilos musicais, considerados “marginais” pela grande indústria e pela pequena indústria, como, por exemplo, o rap e o hip hop, nos EUA (DE MARCHI, 2005; NAKANO, 2010).

Outro impacto importante, apontado por De Marchi (2005), foi causado pela introdução do walkman pela Sony em 1979, que mudou o hábito musical ao trazer a noção da portabilidade da música. Os consumidores podiam ouvir as músicas que desejavam em qualquer lugar.

Agora, porém, a questão envolvia o problema da duplicação não-autorizada, ou, a transferência do conteúdo contido no vinil para o cassete, assim como a gravação não autorizada dos programas de rádios nessas fitas. A dificuldade aumenta já que, diferente de antes, essa reprodução não autorizada acontecia com caráter doméstico e praticamente impossível de ser controlado pelos mecanismos legais e coercitivos então vigentes.

Essa crise representou o interesse do público versus o interesse patrimonial das gravadoras, que se sentiram prejudicadas não apenas com a transferência de conteúdo para a venda ilícita, mas também para o uso próprio dos usuários. Segundo Losso (2008), as gravadoras temiam que ao permitirem que o público transferisse o conteúdo do LP para o cassete, ou até mesmo a duplicação dos cassetes, implicaria na queda das vendas de discos.

\footnotetext{
${ }^{6} \mathrm{O}$ novo formato unia duas inovações incrementais: a gravação em microssulco (cavidades bem mais estreitas por onde a agulha do toca-discos percorre), que diminuía o tamanho dos entalhes na superfície do disco o que aumentou a frequência sonora registrada; e o formato de 33 1/3 rpm (rotações por minuto). Essas duas técnicas associadas proporcionada a gravação de 15 a 20 minutos de som em cada lado de um disco de vinil, contra os 4 minutos do formato 78 rpm (DE MARCHI, 2005).
} 


\section{A ERA DIGITAL E O INÍCIO DE UM NOVO PARADIGMA}

Apesar da indústria fonográfica já ter presenciado diferentes técnicas de gravação (mecânica, elétrica e magnética) e utilizado diferentes formatos de suporte físico, todas essas tecnologias eram enquadradas como tecnologias analógicas ${ }^{7}$. Segundo Witt (2015), com o advento da tecnologia digital na década de 1980 qualquer tipo de informação passou a ser armazenada em fluxo de $b_{i t s}{ }^{8}$. Isso significa que qualquer cópia digital feita a partir de uma matriz seria idêntica a original, sem perda nenhuma na qualidade sonora.

Além disso, a tecnologia digital representou um novo paradigma tecnológico para a indústria da música e exigiu mudanças em todas as etapas da cadeia produtiva, desde os diversos tipos de fornecedores até os consumidores. As inovações digitais afetaram o senso comum das gravadoras e as instituições que são o alicerce desta indústria, no caso, o direito autoral.

A transição da tecnologia analógica para a digital não foi instantânea nem automática, e muito menos a tecnologia digital extinguiu por completo a tecnologia analógica. Ainda é possível ver a produção de $\operatorname{LPs}^{9}$ e até de cassetes ${ }^{10}$.

Em 1982, com o advento do Compact Disc (CD), a expectativa era que o vinil se tornasse rapidamente obsoleto. O CD era mais barato para ser produzido, tinha maior resistência e durabilidade em relação ao LP No entanto, essa substituição não foi imediata e os dois formatos foram comercializados paralelamente. No Brasil, por exemplo, o CD foi introduzido em 1987, mas a venda de LPs pelas grandes gravadoras só parou em 1996, enquanto que a venda de K-7 continuou até 1999 (VICENTE, 2002).

O advento do CD implicou no surgimento da demanda por álbuns clássicos gravados no novo formato. Essa demanda permitiu que as gravadoras lucrassem em cima dos direitos autorais de músicas antigas e investissem num tipo de expansão reversa de seus catálogos. As grandes gravadoras adquiriam as gravadoras independentes e locais para ampliar sua atuação em diversos países. Dessa forma, ganhavam um novo mercado, sem a necessidade de realizar grandes investimentos em novos artistas (HUYGENS, 2009).

\footnotetext{
${ }^{7}$ Tecnologias analógicas são tecnologias que captam uma onda em sua forma original.

${ }^{8}$ Unidades binárias de 0 e 1.

${ }^{9}$ http://www1.folha.uol.com.br/mercado/2016/01/1730917-nova-fabrica-promete-quadruplicar-producao-dediscos-de-vinil-no-pais.shtml. Acesso em 31/01/2016

${ }^{10}$ http://zh.clicrbs.com.br/rs/entretenimento/noticia/2016/02/fitas-cassete-conquistam-o-meio-independente-evoltam-a-ser-produzidas-no-brasil-4970526.html. Acesso em 10/02/2016
} 
Os dados da National Music Publishers Association (NMPA) apud Huygens (2009, p. 273), mostraram que "music-publishing revenues on a worldwide level grew by 10 percent a year from 1982 onwards to more than \$3.5 million by 1990, more than 20 percent of which was accounted for by the United States".

Todavia, como apontado por Losso (2008), muitos dos relançamentos de antigos álbuns para o novo formato foram realizados sem o conhecimento e até sem o devido pagamento aos compositores e intérpretes. As gravadoras alegaram que por serem as titulares dos direitos autorais ou por serem as cessionárias dos direitos patrimoniais, poderiam livremente regravar os álbuns para o novo formato. Era uma mera adequação ao novo formato, o que estava contratualmente respaldada.

Os músicos, por sua vez, se opuseram alegando a falta de autorização e ao nãopagamento dos devidos direitos patrimoniais. Enquanto alguns deles precisaram recorrer ao Poder Judiciário. Porém, pelo entendimento da lei, não havia ato ilícito no relançamento, já que a titularidade dos direitos patrimoniais havia sido transferida para as gravadoras (LOSSO, 2008). Essa interpretação da lei favoreceu as produtoras de fonogramas em detrimento aos interesses dos criadores das obras musicais.

Além disso, a estrutura da indústria fonográfica começou a passar por duas mudanças estruturais. A primeira foi a intensa negociação entre conglomerados de comunicação e de entretenimento que resultaria na concentração do mercado internacional em poucas grandes gravadoras. Na tabela 1 , notamos que no ano em que o $\mathrm{CD}$ foi introduzido no mercado, as seis maiores gravadoras do mundo detinham 55\% do mercado. Em 2000, 81\% do mercado ficou concentrado na mão de cinco gravadoras. Em 2007, quatro empresas foram responsáveis por 74\% do mercado de música gravada, sendo que a Universal detinha mais de $25 \%$ do mercado.

Tabela 2: Participação no mercado mundial das grandes gravadoras da indústria fonográfica

\begin{tabular}{lllllllll}
\hline & 1982 & 2000 & 2002 & 2003 & 2004 & 2005 & 2006 & 2007 \\
\hline Universal & $3 \%$ & $22 \%$ & $25,90 \%$ & $23,5 \%$ & $25,5 \%$ & $25,6 \%$ & $25,7 \%$ & $28,8 \%$ \\
Sony & $13 \%$ & $22 \%$ & $14,10 \%$ & $13,2 \%$ & $21,5 \%$ & $20,5 \%$ & $21,2 \%$ & $20,1 \%$ \\
EMI & $10 \%$ & $12 \%$ & $12 \%$ & $13,4 \%$ & $13,4 \%$ & $13,6 \%$ & $12,8 \%$ & $10,9 \%$ \\
Warner & $8 \%$ & $13 \%$ & $11,90 \%$ & $12,7 \%$ & $11,3 \%$ & $12,8 \%$ & $13,8 \%$ & $14,4 \%$ \\
BMG $^{2}$ & $9 \%$ & $12 \%$ & $11,10 \%$ & $11,9 \%$ & & & & \\
Polygram & $12 \%$ & & & & & & & \\
Subtotal & $55 \%$ & $81 \%$ & $75 \%$ & $74,7 \%$ & $71,7 \%$ & $72,5 \%$ & $73,5 \%$ & $74,2 \%$ \\
Outros & $45 \%$ & $19 \%$ & $25 \%$ & $25 \%$ & $28 \%$ & $28 \%$ & $27 \%$ & $26 \%$ \\
Total & $100 \%$ & $100 \%$ & $100 \%$ & $100 \%$ & $100 \%$ & $100 \%$ & $100 \%$ & $100 \%$ \\
\hline
\end{tabular}


Fonte: LOSSO, 2008, p. 13

${ }^{1}$ Em 1998 a Philips vendeu a gravadora Polygram para a empresa canadense Seagram Company, que já fazia parte da Universal Music Group.

${ }^{2}$ Em 2004, a BMG é adquirida pela Sony Music.

A segunda mudança foi a desverticalização da cadeia produtiva. Poucas empresas puderam arcar com os alto custos para atualizar as manufaturas de discos para a nova tecnologia. Logo, se antes as gravadoras eram responsáveis desde a criação do álbum até a distribuição, a introdução do CD transferiu a produção, o transporte e o armazenamento de discos sob a responsabilidade de empresas terceirizadas. Assim, as gravadoras propriamente ditas passaram a cuidar da seleção dos artistas, criação do álbum, masterização, desenvolvimento das estratégias de marketing, logística de distribuição dos CDs e gestão dos direitos autorais (LOSSO, 2008; NAKANO, 2010).

Se por um lado, a produção em larga escala do CD era viável para poucas empresas, por outro lado, avanços nas tecnologias digitais de produção e reprodução sonora, como sintetizadores, samplers, MIDI, programas de computadores, gravadores de CDs, etc., permitiram a utilização de equipamentos digitais que emulassem todo o processo de gravação de um estúdio profissional, de forma a baratear o processo de gravação para os estúdios amadores e para os próprios músicos, o que revelou-se um incentivo para a criação musical e abriu o mercado para artistas que não eram amparados pelas grandes gravadoras.

\begin{abstract}
O desenvolvimento da informática e sua aplicação na cadeia produtiva das indústrias de equipamentos musicais e de tecnologias de gravação sonora possibilitaram a ampliação do número de estúdios independentes e de micro e pequenas gravadoras. Atualmente, os músicos podem gravar suas composições no computador e produzilas de forma profissional, se quiserem, em estúdios terceirizados. Eventualmente, uma gravadora pode investir nessa produção, sem a necessidade de ter como funcionários contratados qualquer um desses intermediários. Considerando que a adoção do disco óptico (CD) como suporte padrão da indústria de conteúdos digitais igualmente permitiu a abertura de grandes fábricas terceirizadas de reprodução de discos. Assim, gravar e prensar um disco (laser) deixou de ser uma barreira de entrada no mercado fonográfico (DE MARCHI, 2011, p. 117).
\end{abstract}

Portanto, a terceirização da etapa produtiva junto com o barateamento da etapa de criação e gravação permitiram a flexibilização da produção de fonogramas, aumentando o número potencial de gravadoras independentes no mercado. As novas gravadoras geralmente exploravam nichos de mercado que eram desamparados pelas majors, logo, estavam arcando com o risco de investir em novos estilos musicais e novos músicos. Ou seja, não representavam uma concorrência direta com as grandes gravadoras. E se alguma indie obtivesse expressão no cenário musical, logo era incorporada ao portfólio de alguma major. 
É importante ressaltar que as tecnologias responsáveis pelas transformações que o mercado da música presenciou não foram desenvolvidas em atividades de P\&D das próprias gravadoras, mas sim derivadas de inovações radicais e incrementais feitas por grandes empresas de aparelhos eletrônicos domésticos que possuíram ou ainda possuem alguma ligação direta ou indireta com as gravadoras, como é o caso da Sony e da Phillips ${ }^{11}$.

Além disso, mesmo com a facilidade de reproduzir mídias piratas, a indústria fonográfica vivenciou sua melhor fase, com significativo crescimento nas vendas de CDs e aumento nos lucros das gravadoras. Explicado, em parte, pela queda nos custos unitários de produção que não era repassada para o consumidor final.

No fim da década de 1990, aproveitando-se do boom do CD, a indústria fonográfica passou pelos anos mais rentáveis de sua história. A economia transbordava, a demanda agregada era grande e os americanos estavam gastando mais dinheiro em álbuns do que em qualquer outro período. As margens de lucro também aumentavam, pois os ganhos em eficiência com a fabricação de CDs reduziram o custo por unidade dos produtos para menos de 1 dólar — uma economia que não era passada para o consumidor, que pagava 16,98 dólares no varejo. A consolidação na indústria do rádio também ajudava, criando um meio de ouvintes homogêneo em toda a nação, capaz de levar um álbum ao status de platina quase instantaneamente com base em um único sucesso (WITT, 2015, p. 59).

O mesmo foi observado no Brasil. Segundo o estudo de Vicente (2002), que apresentou dados disponibilizados pela ABPD e pelo IFPI, a evolução do número de unidades de fonogramas vendidos no país durante o período de 1966 a 2000 (Gráfico 1) mostra que apesar do início tímido da comercialização de CDs, em 1993 ela superou o comércio de LPs e Cassetes, e a partir de 1995 ela ofereceu um crescimento nunca antes presenciado pela indústria fonográfica nacional.

Gráfico 1: Vendas da indústria fonográfica nacional no período de 1966 a 2000 (por milhões de unidade)

\footnotetext{
${ }^{11}$ A Sony é uma empresa japonesa de aparelhos eletrônicos e também proprietária das gravadoras Sony Music e BMG, além de alguns canais de TV por assinatura. A Phillips, também uma empresa que produz aparelhos eletrônicos e acessórios, já foi proprietária da Polygram que agora faz parte da Universal Music.
} 


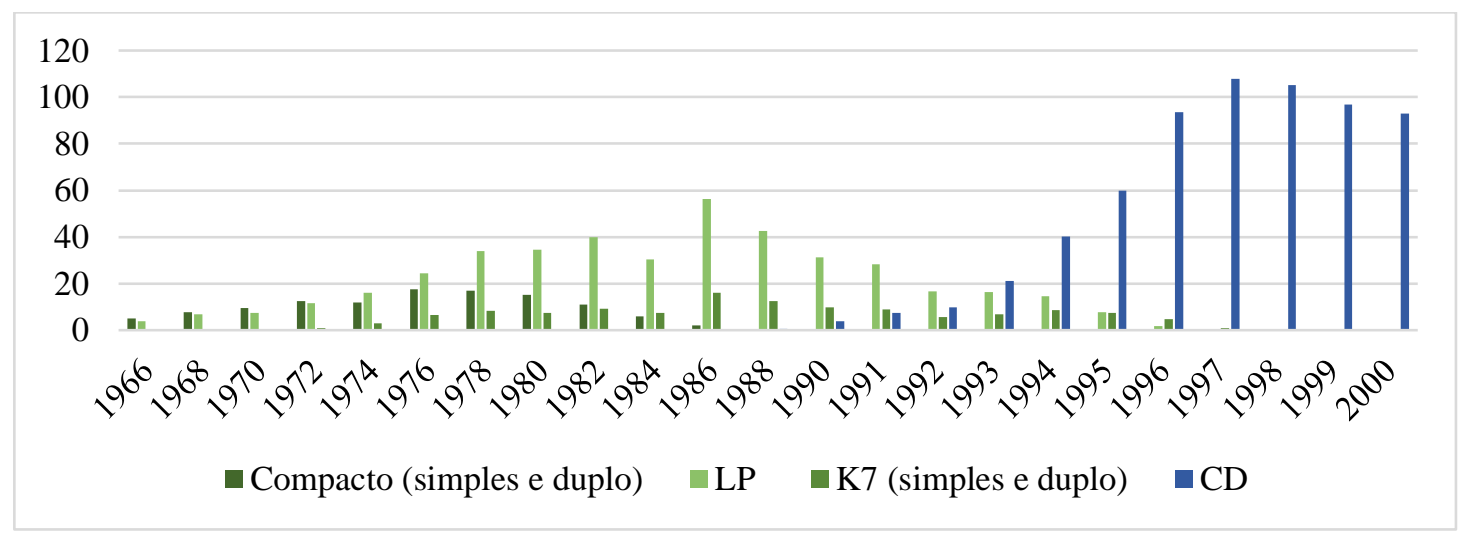

FONTE: VICENTE, 2002. Elaboração própria

O auge da indústria fonográfica foi interrompido com a popularização da internet, dos sites de compartilhamento e a adoção de formatos virtuais.

\section{O IMPACTO DA INTERNET E DOS FORMATOS VIRTUAIS}

As tecnologias digitais reduziram significantemente os custos de gravação a ponto de as pequenas bandas ou pequenos investidores poderem possuir um estúdio próprio ou mesmo um indivíduo, a partir do seu próprio computador pessoal possuir um estúdio caseiro. Se o problema da pirataria se agravara com o CD, a introdução de formatos virtuais, como o MP3 $^{12}$, OGG, WMA entre outros, assim como o alargamento das redes de banda larga e o surgimento de sites de compartilhamento praticamente transformaram a música em um bem público $^{13}$. Ao digitalizar (ou desmaterializar) a música, ela não está mais presa a um suporte físico, podendo facilmente ser transferida de um suporte para outro.

A indústria fonográfica, como observado, consolidou-se com a venda de música, isto é, com a venda de uma mídia (disco de vinil, fita cassete, VHS, CD ou DVD), um objeto material que continha a fixação de músicas. Os formatos virtuais quebraram essa lógica ao permitir que usuários ouvissem suas músicas sem a necessidade de comprar uma mídia. De acordo com De Marchi (2005, 2011), a tecnologia virtual ao transformar a gravação sonora em uma informação transferível entre diferentes suportes transformou o fonograma físico em um bem para armazenamento da informação, o que reduziu seu valor cultural.

\footnotetext{
${ }^{12}$ Segundo Witt (2015, p. 54): "No dia 10 de agosto de 1996, o CDA havia liberado para o IRC o primeiro mp3 'oficialmente’ pirateado: “Until It Sleeps”, do novo álbum do Metallica, Load. Em questão de semanas, já havia inúmeros grupos rivais e milhares de músicas pirateadas”.

${ }^{13}$ Um bem público apresenta as características de não exclusão e não rivalidade, isto é, respectivamente, a impossibilidade de controlar as formas de apropriação do bem ou do serviço pelos diferentes usuários e o fato de que um bem ou um serviço pode ser consumido em sua totalidade por cada membro da sociedade.
} 
A indústria fonográfica começou a sentir a redução do cast de artistas e do quadro de funcionários, o fechamento das produtoras de discos e de lojas de discos; a crise da noção de álbum deixou de ser o principal produto nesta dinâmica de produção e consumo; o desaparecimento de antigas funções na cadeia produtiva (como a de compositor nãointérprete) e, ao mesmo tempo, o surgimento de novas profissões ligadas às novas tecnologias digitais, a volta da valorização dos espetáculos ao vivo e a busca por novos modelos de negócios.

As novas tecnologias de informação e comunicação reduziram os custos marginais de reprodução e distribuição da música, facilitando a infração dos direitos autorais. De acordo com Witt (2015), inúmeros sites começaram a disponibilizar arquivos sonoros em MP3. Inicialmente eram distribuídas músicas de artistas de pouca (ou nenhuma) repercussão na mídia, porém quando alguns sites começaram a oferecer músicas gratuitas protegidas por direitos autorais, a indústria fonográfica americana, representada pela RIAA (Recording Industry Association of America), começou a desenvolver ações para controlar esse fenômeno.

O problema de compartilhamento de músicas on-line agravou-se em 1999, quando o universitário Shaw Fanning criou o Napster, que facilitou a procura de download de arquivos MP3 espalhados na Internet. Segundo Witt (2015), a pirataria musical, antes limitada a uma pequena esfera de usuários com um significativo conhecimento técnico, agora estava disponível para qualquer pessoa. A simplicidade e a fácil utilização desse programa promoveram sua rápida disseminação pelo mundo:

\begin{abstract}
De acordo com a empresa de consultoria estadunidense ComScore Media Metrix, durante o ano de 2000, a empresa (Napster) passou de 3.135 milhões de usuários, no mês de abril, para 10.782, em dezembro do mesmo ano, um crescimento de $343 \%$ e que correspondia a 9,84\% do volume total de usuários de internet naquele país (CALVI, 2008, p. 67). Segundo a mesma pesquisa, nesse momento, o programa distribuía 46,6 milhões de canções por mês, uma média de 1,56 milhões de arquivos por dia (ibid., p. 68). Em seu momento áureo, a empresa deteve vinte e cinco milhões de usuários e oitenta milhões de arquivos. (DE MARCHI, 2011, p. 122)
\end{abstract}

A RIAA processou Fanning por “facilitar a infração dos direitos autorais” ${ }^{14}$, com o apoio de grandes nomes da música. O Napster foi descrito pela acusação como "um serviço de distribuição de conteúdos digitais que concorre, depende e, a um só tempo, debilita o modelo tradicional das indústrias culturais, aproveitando-se de forma oportunista da obra e patrimônio de artistas e gravadoras” (DE MARCHI, 2011, p. 124)

\footnotetext{
${ }^{14}$ Disponível em http://rollingstone.com.br/noticia/metallica-x-napster-aconteceu-ha-8-anos/. Revista Rolling Stones. Visualizado em 4/11/2015
} 
O Napster foi retirado de circulação em 2001. Entretanto, isso não representou o fim de downloads, foi apenas o começo para que vários outros sites de compartilhamento de música. A circulação de música pela Internet sem propósito comercial aumentou ${ }^{15}$, visto a descentralização da tecnologia peer-to-peer ${ }^{16}$, o que dificulta seu bloqueio.

Porém, como observado por De Marchi (2011) e Witt (2015), no mesmo ano em que o Napster se popularizou também foi considerado o ápice para as majors. Mesmo com a crescente pirataria de mídias físicas e o surgimento de sites de compartilhamento, as gravadoras nunca tiveram vendido tantos discos como no período de 1999 e 2000. Uma das razões para isso, é que o consumo de formatos virtuais ainda estava limitado ao uso do computador pessoal. Não havia aparelhos portáteis de MP3, logo, sem a portabilidade, o MP3 ainda era um produto inferior em relação aos CDS. Mesmo que os CDs players pudesse tocar o MP3, e mesmo que pudessem, seria complicado escolher uma música através do menu de CD player. Mas essa situação durou um curto período de tempo.

Segundo Witt (2015) se por um lado o mp3 e os sites de compartilhamento representarem um novo problema para as gravadoras, por outro, empresas de eletrônicos domésticos, como a Diamond Multimedia e a Saehan International - ambas companhias coreanas - viam uma nova oportunidade de negócios: a ideia de produzir um mp3 player portátil.

O advento dos formatos virtuais e suas consequentes inovações alteraram o padrão de consumo da música e isso abriu a possibilidade de novos modelos de negócios em conjunto com diversos meios de comunicação, ampliando o mercado da música a outros setores industrias, como as empresas de telefonia e de produção de softwares e a criação de novos serviços.

Os serviços de streaming, por exemplo, não focam na comercialização da um fonograma, e sim na formação de uma ampla rede de usuários. Empresas desses tipos obtêm seus lucros pela prestação de serviços oferecidos aos usuários e por meio de publicidade. Nesse negócio, os ouvintes deixam de ser consumidores e passam a ser audiência.

De acordo com a IFPI (2013), se em 2010 os serviços de vendas on-line e de streaming estavam presentes em apenas 20 países, em 2012 esse número aumentava para mais

\footnotetext{
${ }^{15}$ Idem

16 A rede peer-to-peer não possui nenhum servidor ou repositório central de informações. Cada computador conectado serve como um servidor, dessa forma, para impedir o tráfego de informações seria necessário interditar cada um desses computadores. O problema é que existem centenas de milhares de computadores conectados no mundo, o que dificulta o controle de informações que são transmitidas na rede, e torna quase impossível a descoberta da origem do arquivo e de quem está compartilhando.
} 
de 100. Os serviços prestados pelo iTunes, Spotify e Deezer são os que mais se destacam. O próprio serviço de streaming está contribuindo com a queda da pirataria, mas também está ajudando a reduzir o consumo de fonogramas. Segundo dados do IFPI ${ }^{17}$, em 2014, temos que 46\% das receitas globais das gravadoras eram provenientes das vendas de suportes físicos, enquanto $46 \%$ eram das vendas digitais (incluindo as receitas dos serviços de streaming).

As novas ferramentas disponíveis em rede permitiram que artistas sem apoio de uma gravadora possam livremente expor seu trabalho na rede. Antes, os canais de divulgação eram controlados pelas principais gravadoras, que muitas vezes utilizaram do jabá para promover seus artistas nas rádios, o principal meio de tornar uma música ou artista conhecida pelo público. Com o avanço das ferramentas disponíveis na Internet, o processo de divulgação se tornou mais democratizado, permitindo a autopromoção dos artistas para um número cada vez maior de potenciais ouvintes sem ter a necessidade de assinar com alguma gravadora (NAKANO, 2010).

Dessa forma, segundo De Marchi (2011), o tradicional papel das gravadoras como intermediários responsáveis por descobrir, desenvolver e promover novos talentos, de produzir as gravações e o produto físico e de distribuí-lo, se mostra ameaçado, visto que o uso generalizado da internet popularizou as redes de distribuição e divulgação da música, quebrando uma barreira a entrada dominada pelas grandes gravadoras.

Podemos perceber, que mais do que um problema de cunho moral e ético, o que preocupa as grandes companhias é o fato de que as inovações digitais e virtuais estão colocando em risco seu poder econômico e seu controle sobre as modalidades de consumo da música. Tem-se que

[...] a inovação foi sempre o fator crítico para o controle do mercado pelas empresas fonográficas e, especificamente, pelas grandes gravadoras. Elas determinavam o passo do desenvolvimento tecnológico e isto lhe concedia um importante poder de barganha com os outros agentes do mercado. O que ficou patente com o caso Napster - e talvez este seja seu grande legado - é que havia um novo contexto no qual todo seu poder e conhecimento pareciam ser inúteis. Havia novas tecnologias, novos hábitos de consumo, novas lógicas sociais de produção, novas estratégias de negócios, outras maneiras de valorizar o capital e outro tipo de empresa que caracterizavam o entorno digital - e tudo isto escapava à sua racionalidade e, por conseguinte, ao seu controle (DE MARCHI, 2011, p. 128).

A música se transformou em um bem quase público. Cabe a legislação observar as demandas por parte da sociedade, como consumidora, e dos criadores e produtores de música e encontrar um equilíbrio a essas demandas, de forma a garantir os incentivos à criação

\footnotetext{
${ }^{17}$ In: http://www.ifpi.org/global-statistics.php. Acesso: 15/10/2015
} 
musical. Como ponderado por Losso (2008, p. 214), a atual crise no direito do autor pode ser resumida como uma tentativa de encontrar um equilíbrio entre

[...] os usuários que pretendem ter acesso gratuito ao farto material musical pela Internet, os compositores e investidores musicais que pretendem ser remunerados e os intérpretes que estão divididos, normalmente entre aqueles que estão em início de carreira ou não atingiram médio nível de êxito e reconhecimento e tanto lhes faz receber ou não, artistas já com certo reconhecimento e que pretendem ser remunerados pela utilização de suas músicas por qualquer meio, inclusive a Internet.

Atualizar as normas que regulam a criação, produção e comércio da música é fundamental para acabar com a persistência da divergência que atualmente existe entre a norma e o comportamento social, visto que isso gera consequências negativas, tanto nas normas (e o sistema jurídico reflexamente) que caem em descrédito, quanto para a sociedade que vive na incerteza sobre quais usos realmente podem fazer das obras protegidas por direito autoral (LEMOS et al, 2011).

\section{CONSIDERAÇÕES FINAIS}

A indústria fonográfica já passou por diferentes reestruturações associadas ao surgimento de uma nova técnica de gravação ou de um novo suporte para a música. O início da indústria fonográfica representou a transformação da música em um produto tangível. Atualmente, a proliferação de inovações ligadas as tecnologias da informação e comunicação estão modificando a forma como consumimos a música, que se desagrega em novos produtos e serviços, como ringtones, videoclipes, licenciamentos, serviços de streaming, etc. E isso abala as estruturas da indústria fonográfica, cuja maior parte dos lucros desde a década de 1940 era oriunda da venda de fonogramas físicos. A partir do ano 2000, a venda de discos vem apresentando queda, enquanto que o consumo de downloads e serviços de streaming cresce. O público apresenta maior poder de escolha do que deseja escutar e maior interação com os artistas.

Enquanto que o período analógico foi um período de formação e consolidação da indústria fonográfica, o paradigma da tecnologia digital e virtual representa a ruptura de seus alicerces. Apesar de muitos falarem sobre o fim da indústria fonográfica, não se diz o fim da criação musical. Pelo contrário, as novas tecnologias abriram um leque de possibilidade para novos modelos de consumo e de negócios a margem da indústria fonográfica. Os artistas não são mais obrigados a assinarem contrato com alguma gravadora para terem seu trabalho reconhecido. 
A atual crise na indústria fonográfica representa uma reestruturação no mercado da música, onde os novos negócios exploram outras vertentes da criação musical, não se limitando ao comércio de fonogramas. No entanto, este processo de reestruturação não é harmônico e muito menos benéfico para todos os agentes envolvidos. Por se tratar de um processo de destruição criadora, temos, por um lado, o fato de que as TIC abriram as possibilidades para novos produtos, serviços, empresas e artistas, além de ampliar os negócios da música para outros mercados (telecomunicações, aparelhos eletrônicos, etc.). Por outro lado, antigos elementos (processos, produtos, empregos, etc.) foram eliminados ou reduzidos no mercado.

\section{REFERÊNCIAS}

DE MARCHI, Leonardo. A angústia do formato: uma história dos formatos fonográficos. Revista da Associação Nacional dos Programas de Pós-Graduação em Comunicação - ECompós, Brasília, v.02, 2005. Disponível em: http://compos.org.br/seer/index.php/ecompos/article/viewFile/29/30.

Transformações estruturais da indústria fonográfica no Brasil 1999-2009:

Desestruturação do mercado de discos, novas mediações do comércio de fonogramas digitais e consequências para a diversidade cultural no mercado de música. Tese de doutorado. Rio de Janeiro, UFRJ, 2011

FREEMAN, Christopher; SOETE, Luc.Aeconomia da inovação industrial. Campinas: Ed. Unicamp, 2008.

FREEMAN, Christopher; PEREZ, Carlota. Structural crises of adjustment, business cycles and investment behaviour. In: DOSI, G.; FREEMAN, C.; NELSON, R.; SILVERBERG, G.; SOETE, L. (Ed.). Technical Change and Economic Theory. London: Pinter Publishers, p. $38-66,1988$.

HUYGENS, Marc et al. Co-evolution of firm capabilities and industry competition: Investigating the music industry, 1877-1997. SAGE Directions in Organization Studies, v. 22, n. 6, p. 249, 2009.

IFPI. Digital Music Report 2013. S.I.: IFPI, 2013.

LEMOS, Ronaldo. Direitos autorais em reforma. Rio de Janeiro: Fundação Getúlio Vargas, 2011.

LOSSO, Fabio Malina. Os direitos autorais no mercado da música. Tese de Doutorado. Universidade de São Paulo. São Paulo. 2008

METCALFE, J. Stanley. Institutions and progress. Industrial and Corporate Change, v. 10, n. 3, p. 561-586, 2001. 
NAKANO, Davi. A produção independente e a desverticalização da cadeia produtiva da música. Revista Gestão Produtiva, São Carlos, v.17, n. 3, p.627-638, 2010. Disponível em: http://www.scielo.br/pdf/gp/v17n3/15.pdf.

PEREZ, Carlota. Technological Revolutions and financial capital: the dynamics of bubbles and Golden ages. Edward Elgar Publishing, 2002.

SCHUMPETER, Joseph A. Capitalismo, Socialismo e Democracia. Editado por George Allen e UnwinLtd., traduzido por Ruy Jungmann. Rio de Janeiro: Editora Fundo de Cultura, 1961.

VICENTE, Eduardo. Música e disco no Brasil: a trajetória da indústria nas décadas de 80 e 90. Tese de Doutorado. Universidade de São Paulo. 2002

WITT, Stephen. Como a música ficou grátis. Editora Intrínseca, 2015. 